\title{
Aprender del miedo
}

\section{Learning from fear}

\author{
Sebastián Rodríguez-Llamazares*
}

*Instituto Nacional de Enfermedades Respiratorias Ismael Cosío Villegas, Ciudad de México.

La vida de estudio y sacrificio de una médica o médico residente no es ningún misterio. Ya hay libros, novelas y series al respecto. Pero quizá, pese a toda esa conciencia de lo que implica, generar empatía hacia su situación nunca sucede de facto. Al fin y al cabo, los médicos especialistas estamos donde estamos porque algún día fuimos residentes. No sólo eso, la vida después nos muestra que ser residente tenía su nivel de romanticismo, de ilusión. Pero ello no le quita contundencia a lo que los residentes de México demuestran diariamente: hace poco más de un año se crearon asambleas para exigir derechos laborales, sin que ello significara desatender a la población que lo requería. Los y las residentes de México caminan y sostienen nuestro sistema de salud a costa de ellos mismos.

Hoy COVID-19 impone nuevas preguntas. Esas preguntas que todo mexicano posee, son las mismas que tienen nuestros médicos y médicas residentes icuánto va a durar esta epidemia? ¿México está preparado? ¿Se están tomando las medidas apropiadas? Y desafortunadamente, pese a todos los años de estudio y todas las guardias realizadas, la respuesta sigue siendo la misma: no lo sabemos.

\section{ENTONCES ¿POR QUÉ ESCRIBIR RESPECTO A LOS MÉDICOS RESIDENTES?}

Porque hay que hablar del miedo. De frente y sin tapujos. Hay que platicar del miedo a contagiarse por un germen que ha demostrado afectar con especial hincapié al personal de salud. Porque aunque la juventud de ser residente parece ser protectora, enfermar significa dejar a tus compañeros solos en el campo de batalla por 14 días. Hay que comentar el miedo de aprender y reaprender a colocarse un equipo de

Correspondencia:

Dr. Sebastián Rodríguez Llamazares

Instituto Nacional de Enfermedades Respiratorias

Ismael Cosío Villegas, Ciudad de México.

Correo electrónico: sebastianrolla@gmail.com

Fecha de recepción: 24-III-2020; aceptado: 12-V-2020. protección personal bajo el que, tras seis horas de trabajo, es imposible continuar ante el peso del sudor y los lentes empañados. Porque el miedo a fallar no está sólo dirigido hacia los pacientes a tu cargo sino hacia los colegas a los que tienes que educar. Hay que dejar de esconder el miedo de ser residente de primer año, desde hace un mes, cuando acabas de empezar; el miedo a no saber qué hacer, abruma aún más que el miedo al propio contagio. Es necesario conversar sobre el miedo a contagiar a las personas que amas, que llega a tal punto que es preferible cambiar de domicilio que contagiar a familiares o compañeros de cuarto. Hay que conocer el miedo de enfrentar una epidemia en medio de la incertidumbre, porque el que hoy haya equipo de protección personal no asegura que mañana vaya a haber.

Y pese al miedo, son y están, no como héroes, pero sí con heroísmo. El peso de ser un héroe es demasiado para cualquiera: aspirar a la perfección es una carga insoportable cuando se está lejos de tomar decisiones correctas y muy cerca de cometer errores. El querer cambiar y mejorar la situación de un paciente que no está en su control lleva a cualquier ser humano al límite de sus emociones. Llegar a casa tras la jornada intensa y mantener la calma al contestar llamadas de amigos y familiares que buscan despejar dudas, es un acto de valentía. Es así como ser residente en tiempos de COVID-19 es un acto de heroísmo, donde todos los días luchan contra sí mismos y contra sus miedos, y esa chispa no vale la pena apagarla, esa es la flama que este país necesita para vencer lo que sea que esta pandemia traiga por delante.

Este es un llamado a cada médica y médico residente que está de pie empezando a combatir esta epidemia. Un llamado para que nos sigan contagiando a luchar contra la incertidumbre. Un llamado a sentir el miedo, a hacerlo suyo, a compartirlo en cada una de sus acciones con la sublimación perfecta hacia la satisfacción del trabajo bien logrado. Cada hora debajo de una bata sintética, cada gota de sudor en el ojo, cada calumnia en los medios por el rechazo de un paciente y cada barba rasurada para hacer que el cubrebocas selle, son hoy la mejor inspiración para no dejarnos vencer. Esperamos estar a la altura de sus enseñanzas. 